\title{
Suicide Attempts and Self-Inflicting on Prison Custody and Prisons
}

\author{
Fatbardha Myslimaj 1 \\ Eglantina Dervishi² \\ ${ }^{1}$ Psychiatrist et Q.S.U.T. \\ ${ }^{2}$ Psychology Department, University of Tirana, Albania
}

\section{Doi:10.5901/ajis.2016.v5n2p175}

\section{Abstract}

This study present some of the cases in Albania that happened during 2005-2012, taken from pre trial detention and prison, focusing on the causes that lead to suicide. To show the number of the cases of suicide in Albania according to pre trial detention and prison of Tirana taken from the records of the General Prison of Tirana for period 2005- 2012, from a research done for pre trial detention and prison. To compare the data according to sex, age, location. Show the suicidal behaviours that these cases show before suicide. To explore the reasons and causes that lead to suicide. To propose a way of stopping this event from happening. The cases that will be shown in this presentation are taken from the office of files and records in the pre trial detention and prison for the city of Tirana, Albania. In this research are not included some cases of falling from great height because it could not be defined by police if it was a suicide or just an accident. Pre trial detention is considered to be more traumatic than prison because the accused one's have to face for the first time with isolation even though they may have been accused injucticly. The stress becomes even more tense also because they have to wait for their trial that will decide their future. During their time there the accused one can feel alone, forgotton, and start blaming themselves. Mean while the imprisoned can handle isolation much better.

Keywords: mental health, suicide, depression, pre trial detention, prision.

\section{Introduction}

What is the contribution of psychopathology in understanding this complex problem? These are some of the questions raised here; unfortunately only vague answers remain. Suicide is a major problem in the world. According to statistics, about 1000000 people kill themselves every year. Over the past 6 decades the number of suicides in the world increased $60 \%$. In Albania the number of people who commit suicide tend to increase during the last decades. This is proven by the statistics published by INSTAT and surveys. 2004-2009 in the number of suicides has increased tendency expressed in absolute figures and in relation to the population. If seen in relation to the population of the country which tends reduction due to emigration (according to the 2011 census the population has fallen below 2.9 million inhabitants), the number of suicides has increased reaching the incidence annual 5.5 / 100,000 inhabitants (in 2003 has been 4/100000 inhabitants).

The study focuses on the factors that influence suicide attempts and self-inflicting institutions execution of criminal sentences and detention. The research shows the impact of conditions and confinement, the situation psycho-emotional detainees [adjustments mind that may impact the use of substances and alcohol abstinence to substances, age, sex, place of residence where they come from, the offenses they have committed.

\section{Epidemiology}

Suicide is a major problem in the world. According to statistics, about one million people commit suicide every year. Over the past 6 decades the number of suicides in the world has increased by $60 \%$ (National Center for Health Statistics,2016). Also in Albania the number of people who commit suicide tend to increase during the last decades. This is proven by the statistics published by INSTAT and different surveys that have been made.In the years 2004-2009 the number of suicides has had a tendency to increase expressed in absolute figures and in relation to the population. If seen in relation to the population of the country which tends to be reducted due to emigration (according to the 2011 census the population has fallen below 2.9 million inhabitants), the number of suicides has increased reaching the annual incidence 5.5 / 100,000 inhabitants (in 2009 it has been 4/100000 inhabitants).Studies made by different authors in different countries of the world, report a very high percentage of suicide in affective disorders was compared with other 
psychiatric disorders. So in about $50-70 \%$ of people who have committed suicide, mood disorders are present, mainly in the depressive phase. The risk to commit suicide is 30 times higher in patients with mood disorders compared to the general population. In these studies it has been highlighted the fact that the suicide risk in mood disorders is about 15\%, and the greater level of risk is in the first 5 years, when patients manifest mood disorders.

Patients with depression with psychotic (Simon, R. \& Hales, R. 2006). features compared to other patients with affective disorders, have a 5 times higher risk for suicide. Even in patients with bipolar depression the suicide rates are found in very high figures, over $20 \%$. The conclusion in which most researchers have achieved is that the predisposing factor for the realization of suicide a situation is not compulsive (Heron M. Deaths, 2016), but it is the presence of depressive sympthomes or mixed episode of bipolar traits, especially paired with symptomatic psychotic. Clinical treatment of patients on psychotropic drugs shows that mixed bipolar conditions are associated especially with a high risk of suicide (Shea, S. 2002) because in this case, committing suicide a favor combination of humor to fallen disforia, high levels of energy and motivation to plans completed suicide. Depression is one of the disorders that often affects children and adolescents. expressed teen Depressive sympthomes expressed on teenagers and children causes more suicides, numbers which these past 30 years have increased significantly.

Clinical symptoms of depression, can be diagnosed with difficulty in adolescents and children. Adults often do not notice signs of depression in their children until they commit a suicidal act. A big number of psycho-social factors (American Psychiatric Association; 2004). contribute in suicidal behavior in children and adolescents, such as age, sex and race.Family factors are considered the most important, that contribute to suicidal behavior in children and adolescents (Roberts SE, Jaremin B, Lloyd K;2013). Concerns, family trauma, disorders on secondment parent-child, physical abuse and sexual abuse by family members, hostilities, difficulties to socializate in schools, etc. lead to the birth of melancholy, sentiment that it is only despair, depression and suicidal behavior encourage.

The studies conducted in the US, refer that the number of suicide in patients with mood disorders is 400 of 100,000 men and 180 women from 100,000 inhabitants. The biggest risk for suicide in affective disorders is in people who are single, divorced, widowed. Approximately $30 \%$ of subjects who commit suicide, who are diagnosed with depression, have in their history, previous suicide attempts. Suicide in depressed patients has a greater risk of happening in those patients who have less prior depressive episodes than those who abuse with drugs and alcohol.

Based on studies conducted over the years, in Albania, suicide actually is a serious problem, because these cases have always been increasing. For this there are several studies and publications forensic aspects, social, legal suicide. The Professor XH.Gjata with collaborators in the study conducted in 1973 reports that suicidal behavior is in the amount of $37.5 \%$.

Dr. D.Totozani in 1974 on the study for suicide, analyzing suicides by patients wiith psychotic problems reports that from 23 suicides, 12 were with endogenous depression . S.Vokopola, with collaborators, the 1974 study showed that from 30 suicides, 5 belonged DEB and 22 to the Depressing Syndrome.

In the study conducted by Dr. N.Polimeri on Endogenous Unipolar Depression in 1979, for a period of 7 years, it was reported a suicide rate of $1.3 \%$ of the patients with DEU in our country. While in the control material, suicidal behavior in patients with DEB is found in 30\% (16).In a study of medico - legal Full Service Central Forensic in Tirana for a period of 40 years from 1958 to 1997, according to the examination of 6206 cases of autopsy of foresic-medicine, suicide occupy $10.4 \%$ of them, with a ratio between males and females about 2: 1, data which are similar to those of foreign literature.From the data we notice that most if the cases are hanging, gunshots fire, poisoning, followed by falling from height, drowning, burning, etc.

Another study of the period of time from 2000-2002, 58 of the 697 deaths examined by Forensic Medicine Institute in Tirana, were suicides cases, most aged 21-40 years. According to the means used to commit suicide, it has been noticed that firearm suicides by hanging and take the first place, followed by falling from heights, helmet and drowning.

In the information, according to data of the years 2008 - 2009 of the Albanian police, suicide throughout the country in recent years, we can identify a very high number of suicide which is constantly increasing.

In the information, according to data of the years 2010 - 2012 of the Albanian police, suicide throughout the country in recent years, we can identify a very high number of suicide which is constantly increasing.

\section{Risk Faktors}

The reason why a person commits suicide almost every time is hard to define. The most common reasons are: Depression, losing hope, diseases, unemployment, the loss of a close person, guilt feeling, breaking up a relationship, psychosis (Windfuhr K, Kapur N; 2011). 
There are a variety of views on suicide. Some, like Albert Camus, claim that the judgment whether life is worth living or not constitutes the only real philosophical question. Others see suicide as the product of a disturbed mind, caused by psychopathological processes. It is probably correct to say that the first systematic study of suicide was carried out by Emile Durkheim, and was published in 1897 in his classic volume Le Suicide (Durkheim, 1897/1952). According to him, suicide is the result of the influence and control of society over an individual. He proposed four types of suicide, each characterized by a particular pattern of tension between the individual and society (Tartaro C and Lester D. (2005).

\section{Results}

Suicide is a psycho-active phenomenon that occurs in all the countries of the world. Currently, suicide is an ungrateful act, considered a paradoxical and disturbing act, a crime against nature, because it denies the instinct of conservation.

The issue of suicide has multiple and various aspects: forensic, ethical, philosophical, sociological and psychiatric, also concerning measures for the treatment and prevention of suicidal attempts by better known suicidal behaviourln 2004 there were 45 cases of suicide are presented. 19 of these cases were females and 26 males. 7 were children, 24 were agreed from 20-40 years old and 21 cases 40 and above. In 2010 there were 25 cases of suicide that were presented 8 of these cases were females and 18 males. 1 case was a children, 9 cases were aged 20-40 years old and 14 cases 40 and above. In 2011 there were 25 cases of suicide that were presented. 10 of these cases were females and 15 males. 3 cases were children, 13 were agreed $20-40$ years old and 26 cases 40 and above.

Mental health is one of the major problems that can cause suicide in Tirana: emotional disorder, depression, stress, anxiety etc. These problems are found in most of the people that committed suicide. They're parents or close friends said that they had one or more of these mental problems. Stigma of the persons that suffer from mental diseases makes them commit suicide.

Unemployment in one of the most common reason of people who commit suicide because of economical problems. These people are traumatised because they lost their job and they have no way of finding a source of wealth so they get depressed very easily. Emigration is also one of the causes that leads people to pessimist thoughts.

Family crises that has touched Albania these last years. This is a common problem to teenagers because the number of divorces is becoming very high.

Getting addicted to something like drugs or alcohol can surely lead someone to suicide. If this addiction gets bigger and bigger every day when the moment comes that that person has to stop he/she becomes aggressive.

Table 1: Suicide attempts and self-inflicting on prison custody and prisons for 2005-2012

\begin{tabular}{|c|c|c|}
\hline Year & Suicides & Self-Infliction \\
\hline 2005 & 2 & 7 \\
\hline 2006 & 1 & 6 \\
\hline 2007 & 0 & 9 \\
\hline 2008 & 1 & 7 \\
\hline 2009 & 0 & 11 \\
\hline 2010 & 1 & 9 \\
\hline 2011 & 2 & 7 \\
\hline 2012 & 2 & 8 \\
\hline Total & 9 & 64 \\
\hline
\end{tabular}

It has been stated that suicide note are fewer in numbers than attempts suicide in prision institutions. The number of suicide varies in the range of $0-2$, while the number of suicide attempts vary from 6 to lower the number the number of suicide. While the total number of suicide attempts is 64 , the number of suicide is 9 .

The number of suicide on the institutions of criminal penalties varies from 0 to 3 and the highest number of suicide was recorded in 2010, which was 3 . The number of suicide attempts in prisons varies from 3 to 8 , and the highest number of suicide occurred in 2006, which consisted in 8 . Even in prisons as pre-trial detention, the number of suicide attempts is higher than suicide, and precisely suicide attempts are 42, while suicide are 6. 


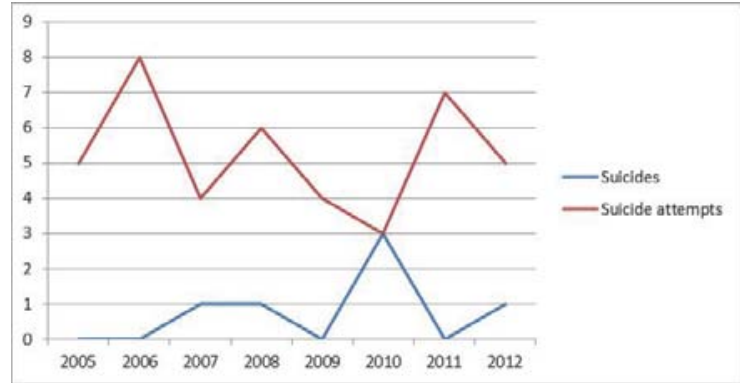

Figure 2: The number of suicide and suicide attempts on the institutions of criminal penalties

Even in this table it is observed that the number of suicide attempts is higher in pre-trial dentention than in prisons and respectively 64 in pre-trial detention and 42 in prisons. Translated into percentages $59.25 \%$ in pre-trial detention and $40.75 \%$ in prisons. This report is very close to the one for the period 2005-2012.

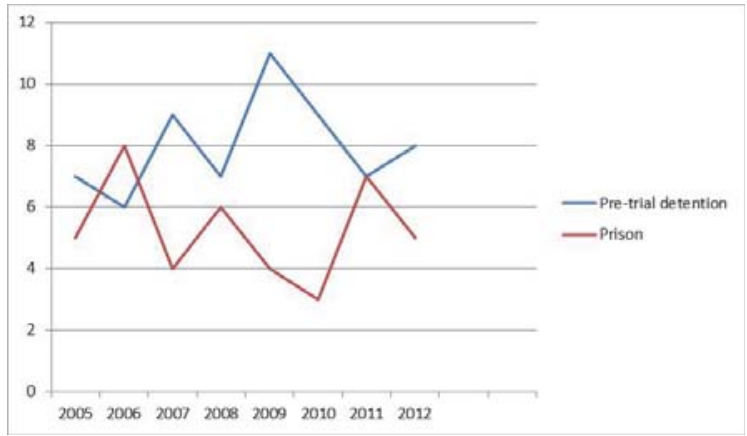

Figure 3: The number of suicide on the institutions on pre-trail detention and prison.

\section{Discussion}

It has been stated that suicide note are fewer in numbers than attempts suicide in prision institutions. The number of suicide varies in the range of $0-2$, while the number of suicide attempts vary from 6 to lower the number the number of suicide which corresponds to the year 2006, 11, which corresponds to the year 2009. While the total number of suicide attempts is 64 , the number of suicide is 9 .

The number of suicide on the institutions of criminal penalties varies from 0 to 3 and the highest number of suicide was recorded in 2010, which was 3 . The number of suicide attempts in prisons varies from 3 to 8 , and the highest number of suicide occurred in 2006, which consisted in 8 . Even in prisons as pre-trial detention, the number of suicide attempts is higher than suicide, and precisely suicide attempts are 42, while suicide are 6.

Even in this table it is observed that the number of suicide attempts is higher in pre-trial dentention than in prisons and respectively 64 in pre-trial detention and 42 in prisons. Translated into percentages $59.25 \%$ in pre-trial detention and $40.75 \%$ in prisons. This report is very close to the one for the period $2005-2012$.

Most suicide attempts do not result in death. Many of these attempts are done in a way that makes rescue possible. These attempts are often a cry for help.

Some people attempt suicide in a way that is less likely to be fatal, such as poisoning or overdose. Males, especially elderly men, are more likely to choose violent methods, such as shooting themselves. As a result, suicide attempts by males are more likely to result in death.

Relatives of people who attempt or commit suicide often blame themselves or become very angry. They may see the suicide attempt as selfish. However, people who try to commit suicide often mistakenly believe that they are doing their friends and relatives a favour by taking themselves out of the world. 


\section{Conclusions}

Suicide is a negative social phenomenon with different aspects of ethics of Philosophy, forensic, psychiatric, legal, social, etc. Its recognition as full and deep will help in the detection, diagnosis, prevention and treatment of rasetve of suicidal attempts. Suicide cases in Albania have always been being increasing which also requires better knowledge of the various aspects of suicide in order to take measures and prevent it. Most suicide attempts do not result in death. Many of these efforts are made in a way that makes salvation possible. These efforts are often a cry for help. There is a rise in the number of suicide attempts as a result of mood disorders, predominantly depressive disorders. In most cases suicidal attempts are accompanied by mood disorders, , hopelessness, negative thinking, self-isolation or self-blame, we can treat to prevent suicide in the context medicated with psychotropic drugs.Familiarity with suicidal behaviors, which are preceded by suicidal thoughts, accompanied by a suicidal plan, is a very important factor in suicidal prevention. It is noted that suicides are fewer in numbers than attempted suicide in detention and the penitentiary (prison). The number of suicide and attempted suicide in detention, is higher than the number of suicide in prisons. A particularly important factor is that the media are being too cautious and reserved in granting news mock suicide to prevent suicide, especially among young people and women as highly vulnerable layers.

\section{Recommendations}

Measures to prevent suicide and attempts sucidive have great importance, especially for those most at risk of suicide, for example young people and adolescents living in difficult social and economic situation, people with weak psychic balance who suffered a concussion, elderly persons living in difficult conditions. Employees of psycho-social care, should be informed about this phenomenon and finding the diagnosis, prevention and treatment for people going through suicidal attempts that have a suicide risk.

For people who have committed suicide attempts should be taken special care at hospitals via somatic treatment, psychiatric, in the first days after the event and later; so they need to feel great care by their relatives. Schools and the media have a greater impact people and children so that they have a great responsibility to inform people about the risk of suicide.

The best thing we can do is to recognize suicidal behaviors to help prevent suicide through human care, and psychosocial professional assistance. We must see this phenomenon in a broader context, health and psychologica . If, as we suspect, some cases of suicidal behavior are not defined 'Psychiatric' then we should be able to slip in this behavior in social cognitive models of so-called normal (theory of planned behavior, health belief model, a model of selfregulation, protection Motivation Theory).

The progress of science, modern face, provides us with an opportunity to rethink the verge our attitudes towards suicide and to integrate significant health instruments, clinical and social psychology to increase our understanding of this complex problem. So the best thing that we can do is to know the suicidal behaviours. Because if we know the behaviours of the people who may attempt to commit suicide we can treat it and prevent it. School and the media have the bigger effect of people and children so they have a big responsibility to inform people about the risks of suicide. It is best for the school to let their students know that they can always talk to someone about their problems and that they're not alone. The media should always remind them that this act can affect not only themselves but also they're family, friends and all the society.So they should always try to help people and mostly children because of the power and effect that they have on them.

"Sometimes even to live is an act of courage" [Seneca]"

\section{References}

American Psychiatric Association. (2004). Practice Guidelines for the Assessment and Treatment of Patients with Suicidal Behaviors. In: Practice Guidelines for the Treatment of Psychiatric Disorders Compendium, 2nd edition. pp. 835-1027. VA: Arlington.

Gjata Xh., Peti A. (1973). Studim kliniko stastikor mbi depresionin dhe psikozen maniakodepresive, Shendetesia Popullore, 3, 57-62.

Heron M. Deaths (2016). Leading causes for 2013. National vital statistics reports; vol 65 no 2. Hyattsville, MD: National Center for Health Statistics. 2016

Morriss R, Kapur N, Byng R, (2013). Assessing risk of suicide or self harm in adults. BMJ. 2013 Jul 25;347:f4572. doi: 10.1136/bmj.f4572.

National Center for Health Statistics. About underlying cause of death, 1999-2014. CDC WONDER online database. 2016. Available from: http://wonder.cdc.gov/ucd-icd10.html. 
Polimcri N. (1979). Depresioni endogjen unipolar, Shendetesia Popullore,18, 47-50.

Roberts SE, Jaremin B, Lloyd K;2013. High-risk occupations for suicide. Psychol Med. 2013 Jun;43(6):1231-40. doi: 10.1017/S0033291712002024. Epub 2012 Oct 26.

Shea, S. (2002). The Practical Art of Suicide Assessment: A Guide for Mental Health Professional and Substance Abuse Counselors. Hoboken, NJ: John Wiley \& Sons.

Simon, R. \& Hales, R. (2006). Textbook of Suicide Assessment and Management. Arlington, VA: American Psychiatric Publishing, Inc.

Tartaro C and Lester D. (2005) An application of Durkheim's theory of suicide to prison suicide rates in the United States. Death Studies 29:413-422.

Totozani D. (1974). Mbi vetevrasjet, Punim psiko-neurologjik, Shendetesia Popullore, (4), 70-5.

Vokopola S. (1974). Turbullimet psikike si shkak i tentativave per vetevrasjeve, Punim psiko-neurologjik, Shendetesia Popullore, (4), 4551.

Windfuhr K, Kapur N; ( 2011) Suicide and mental illness: a clinical review of 15 years findings from the UK National Confidential Inquiry into Suicide. Br Med Bull. 2011;100:101-21. doi: 10.1093/bmb/ldr042. Epub 2011 Sep 22. 